\title{
Fungal peritonitis in peritoneal dialysis: 5-year review from a North China center
}

\author{
Shouci Hu ${ }^{1} \cdot$ Ren Tong ${ }^{1} \cdot$ Yang Bo ${ }^{1} \cdot$ Pei Ming ${ }^{1} \cdot$ Hongtao Yang $^{1}$ (i)
}

Received: 7 April 2018 / Accepted: 22 August 2018 / Published online: 25 August 2018

(c) The Author(s) 2018

\begin{abstract}
Purpose Fungal peritonitis (FP) is a rare but devastating complication in peritoneal dialysis (PD), accounting for high rates of technique failure, morbidity and mortality. This study was conducted to investigate FPs with regard to peritonitis rate, microbiology testing, patient characteristics, clinical features, antifungal treatments, and clinical outcomes in patients on PD. Methods This single-center study retrospectively reviewed all FP episodes diagnosed from June 1, 2012 to June, 2017. All FPs were matched in a 1:5 ratio with PD patients diagnosed with bacterial peritonitis. Clinical, biochemical characteristics and detailed data on peritonitis episodes were recorded.

Results Eleven fungal peritonitis episodes (rate of 0.0067 episodes per patient-year on dialysis) were identified. All FPs were caused by Candida species (identification and antifungal susceptibility testing were performed with VITEK $2^{\circledR}$ compact system), including C. albicans (6/11), C. parapsilosis (4/11) and C. krusei (1/11). Except C. krusei, no Candida resistance to fluconazole was detected. Compared to bacterial peritonitis (matched cases, $n=55$ ), FP group showed higher rate of previous antibiotic use $(p=0.002)$, higher total effluent cell count $(p=0.007)$, and lower serum albumin $(p=0.01)$, higher rate of infection-related surgery $(p<0.001)$, HD transfer $(p=0.001)$, and all-cause death $(p=0.006)$. High prevalence $(\geq 50 \%)$ of female gender, anuria, CCI $\geq 4$, hypoalbuminemia, anemia, and hypokalemia were also observed in FP patients. More than half of the FP patients presented gastrointestinal symptoms (7/11) and extraperitoneal infection (6/11). Eight (72.7\%) patients had catheter surgically removed with a median 5.5 lag days, four (36.4\%) patients died within 3 months and six (54.5\%) cases led to technique failure.

Conclusions FP results in high rates of catheter loss and all-cause mortality in 3 months of follow-up, candida species were the commonest pathogens in our center. Variations of clinical features and susceptibility patterns were observed. Gastrointestinal disorders maybe a potential risk factor for FP.
\end{abstract}

Keywords Fungal peritonitis $\cdot$ Antifungal susceptibility $\cdot$ Antifungal treatment $\cdot$ Peritoneal dialysis

\section{Introduction}

Nowadays, peritoneal dialysis (PD) has become a high quality and cost-effective dialysis modality for patients with endstage kidney disease (ESKD). In the past decade, China has experienced the greatest increase in PD utilization, with the number of PD patients rising steeply from 37,942 in 2012 to 55,373 in 2014 [1]. Unfortunately, PD-related peritonitis, which remains one of the most serious complications for PD,

Hongtao Yang

tjpdyht@163.com

1 Division of Nephrology, First Teaching Hospital of Tianjin University of Traditional Chinese Medicine, Tianjin 300391, China is the leading cause of PD technique failure, accounting for death in around $16 \%$ of PD patients [2-4]. Compared with bacterial peritonitis, fungal peritonitis (FP) is rare, representing only $1-12 \%$ of overall peritonitis in PD patients [5-7], yet devastating and burdened by higher rates of catheter loss, morbidity and mortality $[3,8-10]$. For most FP cases, Candida species are the commonest pathogen, accountable for 70-90\% of FPs in adults [5, 8, 11], where Candida albicans has been classically considered predominant. Nonetheless, there's a rising trend of non-albicans Candida spp. [12-14] and regional, seasonal variation has been reported $[15,16]$. It is widely recognized that intra-abdominal Candida infection, especially Candida peritonitis, may develop invasive candidiasis, boosting mortality rate [17, 18]. Despite the rising concern for FP, its clinical features and treatment still 
have not been well established. Adequate source control and prompt catheter removal are supported by the current guidelines $[3,17,19]$. However, hindered by the lack of specific clinical signs, problematic microbiological diagnosis and treacherous clinical course, management of FP remains challenging.

To our knowledge, studies regarding fungal peritonitis in Chinese PD patients are scarce. Local investigation on history of FP is important for secondary prevention in PD program. In the present study, we systematically reviewed all FP cases in a north china dialysis center between 2012 and 2017. The aim for this study is to evaluate peritonitis rates, deliver descriptive analysis on microbiology testing, patient characteristics and clinical features compared with bacterial peritonitis, antifungal treatments, and outcomes for FP patients.

\section{Subjects, materials and methods}

This is a single-center, retrospective analysis of all prevalent patients who used PD as their first renal replacement therapy (RRT) modality from June 1, 2012 to June 30, 2017 in the PD center of the First Teaching Hospital of Tianjin University of Traditional Chinese Medicine, which is located in northeastern China, along the coast of the Bohai Gulf $\left(39^{\circ} 07^{\prime}\right.$ North, $117^{\circ} 12^{\prime}$ East). Inclusion criteria were patients with ESRD who aged $\geq 18$ years at the start of PD, initiated PD therapy and followed up at our PD center; patients with unwillingness to participate, transfer from permanent $\mathrm{HD}$ ( $\geq 3$ months) were excluded. The enrolled patients were followed up until cessation of PD, death or June 30, 2017.

During June 1, 2012 to June 30, 2017, a total of 744 patients ranging in age from 18 to 91 years were treated by PD at our center. Among whom, 536 incident patients received $\mathrm{PD}$ catheter insertions and initiated PD between June 1, 2012 to June 30, 2017 at our center, 208 prevalent patients (started PD before June, 2012 at our center) with a median vintage of 23 (IQR 10-46.5) months were also recorded. None of these patients had a history of HD therapy for more than 3 months or graft failure. Fourteen incident patients refused to be followed up after catheter insertion. Thus a total of 730 patients who met inclusion criteria were enrolled in the study. All patients were followed for median 23 (IQR 11-42) months up to 5 years through June, 2017. Open surgical techniques for catheter insertion, continuous ambulatory peritoneal dialysis (CAPD) modality was used on all patients. Conventional PD solutions $(1.5 \%, 2.5 \%$, or $4.25 \%$ dextrose) and $Y$ connections with double-bag systems were utilized in all the CAPD patients.

The data were obtained from the PD center database of the First Teaching Hospital of Tianjin University of Traditional Chinese Medicine. Peritonitis episodes and detailed causes for the cessation of PD were recorded from clinical charts. Peritonitis rate and FP rate were expressed as episodes per patient-year. All fungal peritonitis episodes were confirmed by the Lab unit and systematically reviewed for demographics, cause for ESKD, comorbidities, PD duration, presence of potential risk factors for FP (diabetes, immunosuppressive therapy, antibiotic use, previous episodes of peritonitis, or possible bowel source infection), FP confirmation, clinical features (clinical signs, gastrointestinal symptoms, infections besides peritonitis, lab results), antifungal treatment, patient outcomes and clinical courses. Gastrointestinal symptoms were represented by, but not limited to, nausea, vomiting, diarrhea, or abnormalities in stool examination. Extra infections referred to the evidence of extraperitoneal infection found after hospital admission due to fungal peritonitis.

The recorded episodes of peritonitis met at least two of the following three criteria: (1) clinical features of peritonitis; (2) dialysis effluent white cell count (WCC) $>100 / \mu \mathrm{L}$ with $>50 \%$ polymorphonuclear; (3) positive dialysis effluent culture; according to the 2016 International Society for Peritoneal Dialysis (ISPD) recommendations [3] and relapsing episodes defined by ISPD were not counted as another episodes from the prior ones when calculating peritonitis rates.

Microbiology procedures including isolates identification, antifungal susceptibility testing, were performed in the Lab unit, First Teaching Hospital of Tianjin University of Traditional Chinese Medicine. All effluent specimens showing yeasts on Gram's stained smear were inoculated on Sabouraud Dextrose Agar with chloramphenicol and incubated at $35^{\circ} \mathrm{C}$ for $48 \mathrm{~h}$ aerobically. The identification of the yeasts to the species level was performed using the automated method by VITEK $2{ }^{\circledR}$ compact system (bioMérieux, Durham, USA) with VITEK $^{\circledR} 2$ YST card and fully automated testing of susceptibility to amphotericin B, 5-flucytosine, fluconazole, voriconazole, and itraconazole were subsequently carried out on VITEK $2^{\circledR}$ compact with VITEK ${ }^{\circledR} 2$ AST-YST card following the manufacturer's recommendations. DensiChek standard calibration kit (bioMérieux) was used for the preparation of the fungal inoculum, and the inoculum suspensions for the VITEK $2^{\circledR}$ were prepared in $0.45 \%$ saline at turbidity equal to a 2.0 McFarland standard. The test cards were automatically filled with the prepared culture suspension, sealed, and incubated for $18-72 \mathrm{~h}$ at $35^{\circ} \mathrm{C}$ by VITEK $2^{\circledR}$ compact and read every $15 \mathrm{~min}$. The analysis and interpretation of data were performed according to the criteria of the M27-A3 guidelines of the Clinical and Laboratory Standards Institute (CLSI) [20]. The interpretive criteria for susceptibility to antifungal agents were as follows: for fluconazole, MIC $\leq 2 \mathrm{~g} / \mathrm{ml}$ were considered susceptible (S), MIC $\geq 8 \mathrm{~g} / \mathrm{ml}$ were resistant (R) and 4 $\mathrm{g} / \mathrm{ml}$ as susceptible-dose dependent (SDD) in C. albicans and C. parapsilosis; for voriconazole, $\mathrm{S}, \leq 0.125 \mathrm{~g} / \mathrm{ml}$, intermediate (I), 0.25-0.5 g/ml, R, $\geq 1 \mathrm{~g} / \mathrm{ml}$ in C. albicans and $C$. 
parapsilosis whereas in C. krusei, $\mathrm{S}, \leq 0.5 \mathrm{~g} / \mathrm{ml}, \mathrm{I}, 1 \mathrm{~g} / \mathrm{ml}, \mathrm{R}$, $\geq 2 \mathrm{~g} / \mathrm{ml}$; for itraconazole, $\mathrm{S}, \leq 0.125 \mathrm{~g} / \mathrm{ml}$, SDD, $0.25-0.5 \mathrm{~g} /$ $\mathrm{ml}, \mathrm{R}, \geq 1 \mathrm{~g} / \mathrm{ml}$ in C. albicans, epidemiologic cut-off values (ECV) were $0.5 \mathrm{~g} / \mathrm{ml}$ in C. parapsilosis and $1 \mathrm{~g} / \mathrm{ml}$ in C. krusei; for 5-flucytosine, $\mathrm{S}, \leq 4 \mathrm{~g} / \mathrm{ml}, \mathrm{R}, \geq 32 \mathrm{~g} / \mathrm{ml}$ (ECV 0.5-1 $\mathrm{g} / \mathrm{ml}$ in most candida species, except in C. krusei were $32 \mathrm{~g} /$ $\mathrm{ml}$ ); for amphotericin B, ECV was $2 \mathrm{~g} / \mathrm{ml}$ in each species of Candida, and putative clinical breakpoints were $\mathrm{S}, \leq 1 \mathrm{~g} / \mathrm{ml}$ and $\mathrm{R},>1 \mathrm{~g} / \mathrm{ml}$.

The management of FP including empiric antifungal selection, antifungal regimen, adjunctive treatments, and catheter removal was based on the patients' clinical status, adjusted for culture results and susceptibilities, according to the guidelines of ISPD with a combination of our center's experience.

For comparison's sake, all fungal peritonitis cases were matched in a 1:5 ratio with patients diagnosed with $P D$ related bacterial peritonitis, occurring close to each fungal episode in time. The data for 1:5 matching were generated from hospital information system and merged to our PD center database.

Data on patient demographics, major comorbidities (diabetes, cardiovascular disease), Charlson comorbidity index (CCI), PD duration at the onset of peritonitis episode, immunocompromised history, previous antibiotic use within the preceding 3 months were recorded. Clinical and biochemical data including body mass index (BMI), potassium, calcium, phosphorus, intact parathyroid hormone (iPTH), serum albumin, glucose, creatinine, urea nitrogen, hemoglobin, C-reactive protein (CRP), 1 -3- $\beta$-D-glucan, blood WCC, total effluent cell count, effluent WCC (with the percentage of polymorphonuclear), and 24-h urine output were also recorded. Infection-related surgery during the hospital stay, transfer to hemodialysis, and all-cause mortality in 3 months were included for the comparison of patients' clinical outcomes.

Median (interquartile range, IQR) or count with percentage was determined for patient demographics, laboratory parameters, and outcomes when appropriate. Differences between fungal peritonitis and bacterial peritonitis groups were evaluated by Student's $t$ test for parametric data, Mann-Whitney $U$ test for nonparametric data and Fisher's exact test for comparisons of percentages between groups, as appropriate. Statistical analyses was performed using IBM() SPSS $^{\circledR}$ Statistics Version 25. A $p$ value $<0.05$ was considered statistically significant.

\section{Results}

During June 1st, 2012 to June 30th, 2017, a total of 730 prevalent PD patients was enrolled, among whom, 264 (36.2\%) patients experienced at least 1 episode of peritonitis and 11
(1.51\%) patients developed FP during the follow-up. By the end of June, 2017, a total of 436 peritonitis episodes had been identified, including 11 (2.5\%) episodes of FP and 311 (71.3\%) episodes of bacterial peritonitis, and a total of 277 PD patients dropped out of PD, with the aggregated followup of 19,665 patient-months for all prevalent patient, corresponding to a peritonitis rate of 0.266 episodes per-patient year and an FP rate of 0.0067 episodes per patient-year.

\section{Causative organisms for FP}

All FP cases were caused by Candida species, where Candida albicans was accountable for six (54.5\%) cases, Candida parapsilosis was the causative organism in four (36.4\%) cases, and Candida krusei was identified in one $(9.1 \%)$ case. Organism identification and antifungal susceptibility testing results are shown in Table 1. The MIC range for fluconazole, itraconazole and voriconazole in $C$. albicans and $C$. parapsilosis was $1.0-2.0 \mu \mathrm{g} / \mathrm{mL}, 0.125-0.500 \mu \mathrm{g} / \mathrm{mL}$ and $0.25-0.50 \mu \mathrm{g} / \mathrm{mL}$, respectively. One $C$. albicans showed resistant MIC of $2 \mu \mathrm{g} / \mathrm{mL}$ to amphotericin B. Susceptible dose-dependent MIC range of $0.25-0.5 \mu \mathrm{g} / \mathrm{mL}$ for itraconazole were observed in two isolates of $C$. albicans, and MIC range for voriconazole in $C$. albicans and C. parapsilosis were relatively higher, within intermediate range. All $C$. albicans and $C$. parapsilosis presented decreased susceptibilities to 5-flucytosine with MIC of $4 \mu \mathrm{g} / \mathrm{mL}$. In the FP case caused by $C$. krusei, to which the resistance to fluconazole is intrinsic, $C$. krusei showed resistance to fluconazole and itraconazole whereas to voriconazole was susceptible.

\section{Comparison of the fungal and bacterial peritonitis}

Demographic, clinical characteristics, laboratory parameters and clinical outcomes associated with fungal and bacterial peritonitis are summarized in Table 2. More than half of the FP patients were female, with CCI equal or greater than 4 , comorbid cardiovascular disease, or anuric. When compared with bacterial peritonitis group, FP group showed higher rate of previous antibiotic use, higher total effluent cell count, and lower serum albumin. When comparing clinical outcomes between the two groups, FP group showed higher rate of infection-related surgery, HD transfer and all-cause mortality.

\section{Details of the FP cases}

Detailed information on $11 \mathrm{FP}$ cases were provided in Table 3. One patient with systemic scleroderma was under immunosuppressive therapy (oral administration of methylprednisolone, $4 \mathrm{mg}$, Qd). On admission, all patient presented cloudy effluent with effluent WCC $\geq 390 / \mathrm{L}$ and $\mathrm{PMNl} \geq 80 \%$. Fever and hypotension were present in 45.5 
Table 1 Susceptibility results of the Isolates from 11 fungal peritonitis cases

\begin{tabular}{llllll}
\hline Organism identification & \multicolumn{5}{l}{ Antifungal susceptibility testing [MIC $(\mu \mathrm{g} / \mathrm{mL})]$} \\
\cline { 2 - 6 } & Amphotericin B & 5-Flucytosine & Fluconazole & Itraconazole & Voriconazole \\
\hline Candida parapsilosis & 1.0 & 4.0 & 2.0 & 0.125 & $0.25 \mathrm{I}$ \\
Candida albicans & $2.0 \mathrm{R}^{\mathrm{a}}$ & 4.0 & 1.0 & 0.500 SDD & $0.25 \mathrm{I}$ \\
Candida parapsilosis & 1.0 & 4.0 & 2.0 & 0.125 & $0.50 \mathrm{I}$ \\
Candida parapsilosis & 1.0 & 4.0 & 2.0 & 0.250 & $0.50 \mathrm{I}$ \\
Candida albicans & 1.0 & 4.0 & 2.0 & 0.125 & $0.50 \mathrm{I}$ \\
Candida albicans & 1.0 & 4.0 & 2.0 & $0.250 \mathrm{SDD}$ & $0.50 \mathrm{I}$ \\
Candida parapsilosis & 1.0 & 4.0 & 2.0 & 0.125 & $0.50 \mathrm{I}$ \\
Candida albicans & 1.0 & 4.0 & 2.0 & 0.125 & $0.50 \mathrm{I}$ \\
Candida albicans & 1.0 & 4.0 & 2.0 & 0.125 & $0.50 \mathrm{I}$ \\
Candida kruse ${ }^{\mathrm{b}}$ & 1.0 & 4.0 & $128.0 \mathrm{R}$ & $4.000 \mathrm{R}$ & 0.50 \\
Candida albicans & 1.0 & 4.0 & 2.0 & 0.125 & $0.50 \mathrm{I}$ \\
\hline
\end{tabular}

$M I C$ minimum inhibitory concentration, $R$ resistant, $S D D$ susceptible dose-dependent, $I$ intermediate

${ }^{a}$ Putative resistance MIC range $>1 \mu \mathrm{g} / \mathrm{mL}$

${ }^{\mathrm{b}}$ Candida krusei is intrinsically resistant to fluconazole and $27.3 \%$ of the patients, respectively. Hypoalbuminemia, anemia and hypokalemia were observed in more than half (54.5-72.7\%) of the patients. Seven (63.6\%) patients had gastrointestinal symptoms, including nausea, vomiting, diarrhea, or abnormalities in stool examination. One patient with intestinal perforation had critical signs of disseminated intravascular coagulation, condition of whom worsened aggressively. Extraperitoneal infection was found in six $(54.5 \%)$ patients, including respiratory tract infection (2/6), pulmonary infection (1/6, growth of Candida from respiratory secretions was reported), pressure ulcer (1/6), gangrene (1/6), gastroenteritis (5/6) and cholecystitis (1/6). Summarized patient characteristics and clinic features are illustrated in Fig. 1, the black bars refer to the variables with higher frequency $(>50 \%)$.

None of these patients had received antifungal prophylaxis. As the growth of yeast in the PD fluid culture reported after admission, initial treatment with IP fluconazole was observed in eight patients, two patients were administrated with IV fluconazole and one patient with oral administration of fluconazole initially. IV administration of caspofungin was used in two patients and other nine patients were administrated with IV fluconazole. Eight patients had oral regimen added to antifungal treatment. Except for three patients, PD catheter was surgically removed in all patients with a median lag time of 5.5 (IQR, 4-11) days between FP diagnosis and catheter removal. The median hospital stay for all FP cases was 22 (IQR, 17-30.5) days. Six patients survived after FP episode but switched to HD permanently. Only one patient survived FP and still continued on PD with an uneventful recovery. Four patients died within 3 months after FP diagnosis.

\section{Discussion}

In contrast to bacterial peritonitis, FP is relatively uncommon in PD patients. Our 5-year review showed only $11(2.5 \%)$ cases of FP in a total of 436 episodes of peritonitis, demonstrating a rate of 0.0067 episodes per patient-year for FP and all patients were not treated with antifungal prophylaxis. FP rate varied from centers and regions. One cohort study from a north American PD center reported a rate of 0.018/patient year for FP with $24 \%$ of the FP patients using fungal prophylaxis [5]. An audit study from UK reported an FP rate of 0.0099/ patient year from centers not using prophylaxis [21] and a relatively lower rate of $0.0032 /$ patient year in centers using antifungal prophylaxis with daily oral fluconazole. Another single-center study from South Korea, reported an FP rate of 0.02/patient year [22] and a similar rate was also reported in one study from Australia [7].

Previous peritonitis episodes, prior use of antibiotics, immunosuppressed state, diabetes mellitus, malnutrition and prolonged time on PD are common risk factors for FP [14, 23]. Lower serum albumin level, higher prevalence of previous antibiotic use, and higher effluent cell count were observed in FP patients when compared with bacterial peritonitis. Another case matching (1:2) study with a larger dataset (FP vs bacterial peritonitis, 39:78) from Australia [7] reported that FP patients had higher prevalence of longer PD duration, previous bacterial peritonitis episodes and antibiotic use, longer hospital stay, PD catheter removal and permanent transfer to HD; but all-cause 30-day mortality was comparable between fungal and bacterial peritonitis groups. A 10-year retrospective 
Table 2 Comparison of patients with fungal versus bacterial peritonitis (1:5 ratio matching)

\begin{tabular}{|c|c|c|c|}
\hline Variable & $\begin{array}{l}\text { Fungal peritonitis } \\
n=11 \\
\text { Median (IQR) or } n(\%)\end{array}$ & $\begin{array}{l}\text { Bacterial peritonitis } \\
n=55 \\
\text { Median (IQR) or } n(\%)\end{array}$ & $P$ value \\
\hline Age (years) & $62(54-70)$ & $62(52-67)$ & 0.692 \\
\hline Age $\geq 65$ & $5(45.45 \%)$ & $21(38.18 \%)$ & 0.741 \\
\hline Female gender & $7(63.64 \%)$ & $29(52.73 \%)$ & 0.742 \\
\hline Diabetes & $4(36.36 \%)$ & $24(43.64 \%)$ & 0.747 \\
\hline Cardiovascular disease & $9(81.82 \%)$ & $45(81.82 \%)$ & 1.000 \\
\hline $\mathrm{CCI} \geq 4$ & $7(63.64 \%)$ & $23(41.82 \%)$ & 0.206 \\
\hline BMI $\left(\mathrm{kg} / \mathrm{m}^{2}\right)$ & $20.45(18.35-25.21)$ & $23.52(20.75-25.34)$ & 0.249 \\
\hline PD duration (months) & $43(22-52)$ & $35(24-49)$ & 0.795 \\
\hline Under immunosuppressive therapy & $1(9.09 \%)$ & $4(7.27 \%)$ & 1.000 \\
\hline Previous antibiotic use $\mathrm{a}^{\mathrm{a}}$ & $5(45.45 \%)$ & $3(5.45 \%)$ & 0.002 \\
\hline Potassium $(\mathrm{mmol} / \mathrm{L})$ & $3.40(3.20-3.50)$ & $3.70(3.15-4.30)$ & 0.163 \\
\hline Calcium (mmol/L) & $2.10(1.98-2.46)$ & $2.13(2.03-2.26)$ & 0.973 \\
\hline Phosphorus (mmol/L) & $1.19(0.99-1.40)$ & $1.31(1.05-1.63)$ & 0.480 \\
\hline Glucose (mmol/L) & $7.56(6.07-9.56)$ & $7.05(5.54-8.57)$ & 0.414 \\
\hline Serum creatine $(\mu \mathrm{mol} / \mathrm{L})$ & $608.90(549.96-737.86)$ & $746.82(604.59-876.22)$ & 0.100 \\
\hline Blood urea nitrogen $(\mathrm{mmol} / \mathrm{L})$ & $15.71(13.40-21.45)$ & $17.08(13.78-22.18)$ & 0.695 \\
\hline Serum albumin $(g / L)$ & $24.90(22.90-29.95)$ & $32.00(28.35-35.40)$ & 0.010 \\
\hline Hemoglobin (g/L) & $98.00(86.00-108.00)$ & $98.00(88.50-104.50)$ & 0.870 \\
\hline iPTH $(\mathrm{pg} / \mathrm{mL})$ & $215.10(172.70-276.30)$ & $331.00(204.40-643.20)$ & 0.353 \\
\hline Blood WCC $\left(10^{9} / \mathrm{L}\right)$ & $10.95(7.38-11.24)$ & $7.67(5.67-11.39)$ & 0.163 \\
\hline Total effluent CC $\left(10^{6} / \mathrm{L}\right)$ & $1920(1545-3355)$ & $720(350-1565)$ & 0.007 \\
\hline Effluent WCC $\left(10^{6} / \mathrm{L}\right)$ & $1760(880-2955)$ & $1180(360-1725)$ & 0.058 \\
\hline $\operatorname{PMN}(\%)$ & $90.00(85.00-90.00)$ & $90.00(80.00-90.00)$ & 0.435 \\
\hline $\mathrm{CRP}(\mathrm{mg} / \mathrm{L})$ & $148.00(119.75-186.00)$ & $95.20(23.00-171.00)$ & 0.099 \\
\hline $1-3-\beta$-D-Glucan $(\mathrm{pg} / \mathrm{mL})$ & $70.25(49.62-82.94)$ & $49.20(42.16-52.50)$ & 0.054 \\
\hline Anuric & $6(54.55 \%)$ & $18(32.73 \%)$ & 0.189 \\
\hline Urine output (mL/day) & $0.00(0.00-500.00)$ & $200.00(0.00-500.00)$ & 0.503 \\
\hline \multicolumn{4}{|l|}{ Clinical outcome } \\
\hline Infection-related surgery & $8(72.73 \%)$ & $5(9.09 \%)$ & $<\mathbf{0 . 0 0 1}$ \\
\hline Transfer to HD & $6(54.55 \%)$ & $4(7.27 \%)$ & 0.001 \\
\hline All-cause mortality ${ }^{\mathrm{b}}$ & $4(36.36 \%)$ & $2(3.64 \%)$ & 0.006 \\
\hline
\end{tabular}

$I Q R$ interquartile range, $C C I$ Charlson comorbidity index, $B M I$ body mass index, $P D$ peritoneal dialysis, $i P T H$ intact parathyroid hormone, $W C C$ white cell count, $C C$ cell count, $P M N$ polymorphonuclear, $C R P$ C-reactive protein, $H D$ hemodialysis

Boldface indicates $p$ values less than 0.05 , which are considered statistically significant

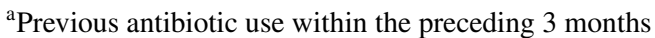

${ }^{\mathrm{b}}$ All-cause mortality in 3 months study from turkey [24] reported that PD obligatory choice due to access or medical problems and lower serum albumin level were significantly related with FPs.

Moreover, our study showed high prevalence of female gender, anuria, high CCI, hypoalbuminemia, anemia, and hypokalemia in FP patients. Presence of DM, elder age, underweight, previous episodes of bacterial peritonitis and recent antibiotic use were also noticeable in these cases.

Concerns over female gender and PD-related infection has been discussed in several studies [25, 26], however, the association between gender and peritonitis risk related to fungi is unclear. Higher burden of comorbidities, loss of residual kidney function, longer PD duration were identified factors associated with FP in previous studies $[5,22]$. The association between aging and peritonitis remains controversial [27, 28], a 10-year cohort study from Taiwan revealed that aged over 65 was the only independent risk factor associated with the incidence of peritonitis [29]. On the other hand, factors such as diabetes, malnutrition, comorbidities, hypoproteinemia and anemia are well-established risk factors associated with mortality. In FP cases, the presence of these factors may exacerbate 
Table 3 Detailed information on 11 fungal peritonitis cases

\begin{tabular}{|c|c|c|}
\hline Case details & Count/no. of patients (\%) & Extra information \\
\hline \multicolumn{3}{|l|}{ Primary cause for ESKD } \\
\hline CGN & $4 / 11(36.4 \%)$ & \\
\hline PKD & $1 / 11(9.1 \%)$ & \\
\hline $\mathrm{SSc}$ & $1 / 11(9.1 \%)$ & Immunocompromised \\
\hline DKD & $3 / 11(27.3 \%)$ & \\
\hline Unknown & $1 / 11(9.1 \%)$ & \\
\hline Had previous peritonitis episodes & $5 / 11(45.5 \%)$ & Median (IQR) individual peritonitis rate ${ }^{\mathrm{a}}: 0.00(0.00-0.23)$ per patient-year \\
\hline Cloudy effluent & $11 / 11(100 \%)$ & \\
\hline Abdominal pain & $9 / 11(81.8 \%)$ & \\
\hline Fever & $5 / 11(45.5 \%)$ & \\
\hline Hypotension & $3 / 11(27.3 \%)$ & \\
\hline Hypoalbuminemia & $8 / 11(72.7 \%)$ & Serum albumin reached severe low level $(<25 \mathrm{~g} / \mathrm{L})$ in 6 patients \\
\hline Anemia & $8 / 11(72.7 \%)$ & \\
\hline Hypokalemia & $6 / 11(54.5 \%)$ & \\
\hline Gastrointestinal symptom $^{\mathrm{b}}$ & $7 / 11(63.6 \%)$ & One patient developed intestinal perforation \\
\hline With extra infection ${ }^{c}$ & $6 / 11(54.5 \%)$ & $\begin{array}{l}\text { Respiratory tract infection, pulmonary infection, pressure ulcer, gangrene, } \\
\text { gastroenteritis, and cholecystitis }\end{array}$ \\
\hline Early treatment with IP fluconazole & $8 / 11(72.7 \%)$ & \\
\hline Fluconazole as IV choice & $9 / 11(81.8 \%)$ & \\
\hline Caspofungin as IV choice & $2 / 11(18.2 \%)$ & \\
\hline Had oral antifungal administration & $8 / 11(72.7 \%)$ & \\
\hline Catheter removal & $8 / 11(72.7 \%)$ & Median (IQR) lag time to removal: $5.5(4.0-11.0)$ days \\
\hline Hospital stay due to $\mathrm{FP} \geq 30$ days & $3 / 11(27.3 \%)$ & Median (IQR) hospital stay: 22.0 (17.0-30.5) days \\
\hline Permanently on HD after FP & $6 / 11(54.5 \%)$ & \\
\hline All-cause death in 3 months & $4 / 11(36.4 \%)$ & \\
\hline
\end{tabular}

ESKD end-stage kidney disease, $C G N$ chronic glomerulonephritis, $S S c$ systemic scleroderma, $P K D$ polycystic kidneys, $D K D$ diabetic kidney disease, $I Q R$ interquartile range, $I P$ intraperitoneal, $I V$ intravenous, $F P$ fungal peritonitis, $H D$ hemodialysis

${ }^{a}$ Individual peritonitis rate was calculated as episodes per patient-year at risk

${ }^{\mathrm{b}}$ Gastrointestinal symptom includes nausea, vomiting, diarrhea, or abnormal findings from stool examination

${ }^{\mathrm{c}}$ Extra infection refers to the evidence of extraperitoneal infection found after hospital admission due to fungal peritonitis

patients' condition rather than infection itself, causing poor prognosis for FPs.

Gastrointestinal disorders in FP cases is common in our center, $63.6 \%$ cases presented gastrointestinal symptoms, $45.5 \%$ cases had extraperitoneal infection of gastroenteritis and one case reported bowel perforation. Another evidence is the prevalence of hypokalemia in our study. Hypokalemia has been considered to be associated with impaired bowel motility and bacterial overgrowth [30], lower level of potassium was reported in studies as a risk factor for peritonitis [31, 32]. Gut dysfunction, transmural migration of enteric organisms and potential breach from the gastrointestinal tract not only pose high risk to FP but complicate the cases of FP as well. Whether the management of gastrointestinal disorders could reduce the risk of FP requires further study.

Candida species were accountable for all FPs in our center, and Candida albicans was the major causative organism. We identified one case of Candida krusei, which is intrinsically resistant to fluconazole and rarely seen in FPs. Report from China Hospital Invasive Fungal Surveillance Net study in 2015 showed zero number of C. krusei isolates from peritoneal dialysate fluid [12], all C. krusei isolates from the study were susceptible/ WT to amphotericin B, flucytosine, voriconazole, and itraconazole. Data from the SENTRY antifungal surveillance program [33] (2010-2012) reported in vitro antifungal susceptibilities of Candida spp. isolates in China, showing resistance to amphotericin B $(0.0 \%)$, flucytosine $(0.0-1.7 \%)$, fluconazole $(0.0-10.3 \%)$, itraconazole (0.0-3.4\%), and voriconazole $(0.0 \%)$ in C. albicans and C. parapsilosis. Varying susceptibility patterns were observed in our study: One Candida albicans showed resistance to amphotericin $\mathrm{B}$, two isolates of $C$. albicans had susceptible dose-dependent range for itraconazole, intermediate range for voriconazole in $C$. albicans and C. parapsilosis were observed and all Candida species 
Fig. 1 Summarized patient characteristic and clinical features of the 11 fungal peritonitis cases. $P D$ peritoneal dialysis, $W B C$ white blood cell

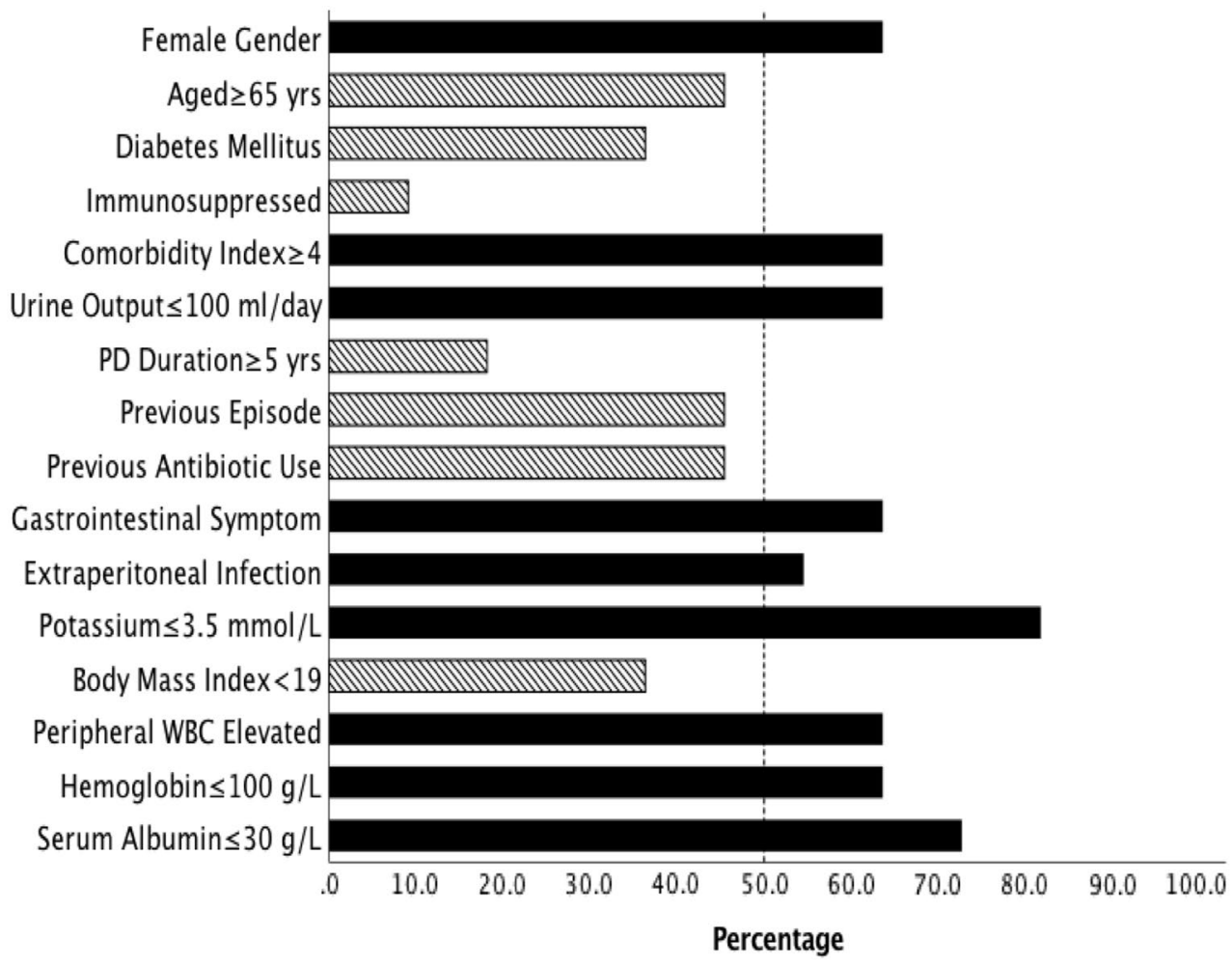

presented decreased susceptibilities to 5-flucytosine, whereas no Candida resistance to fluconazole was detected except for $C$. krusei.

Fluconazole is the first-line agent for initial empiric therapy in FPs. As the fluconazole-resistant Candida spp. tend to increase, the updated Infectious Diseases Society of America (IDSA) guideline strongly recommends an echinocandin as initial therapy for intra-abdominal candidiasis, yet cost-effectiveness considerations may hamper the widespread of such practice in developing countries [17, 34]. In our study, fluconazole was used in most cases for initial therapy and later antifungal regimen, whereas echinocandins (caspofungin) was only used in two cases. Whether the use of echinocandins can improve patient survival and the restart rate of $\mathrm{PD}$ requires further study.

With $72.7 \%$ of the patient having catheter removed in a median 5.5 lag days, poor outcomes of FPs were observed in our study. Rates of infection-related surgery, HD transfer, and all-cause mortality are significantly higher in FPs when compared with bacterial peritonitis group. $36.4 \%$ of the FP patients died within 3 months and only one patient is still active on PD. Another study from a North American PD center [5] demonstrated a significant proportion (33\%) of restart on PD, suggesting the importance of revisiting and reassessing the suitability for PD after FPs.

\section{Conclusion}

To conclude, FP is rare but results in high rates of technique failure and death. Candida species were the commonest pathogens in our center. Variable clinical features and antifungal susceptibility patterns were reported. Gastrointestinal disorders maybe a potential risk factor for FPs. Further studies of FP regarding the selection of antifungal agents, optimized treatment, efficacy of managing modifiable risk factors, improving patient outcomes and returning rate for $\mathrm{PD}$ are in demand.

Acknowledgements We would like to thank all the hard-working doctors and nurses in our PD center for their excellent medical care and the assistance in data collection. All authors had access to the data and a role in writing the manuscript.

Funding This work was supported by the National Natural Science Foundation of China (Grant no. 81373851) and Tianjin Science and Technology Program (Grant no. 15ZXLCSY00020).

\section{Compliance with ethical standards}

Ethical approval The authors declare that ethical approval was not required. The study was performed retrospectively only using electronic data from the PD center database of the First Teaching Hospital of Tianjin University of Traditional Chinese Medicine. The patients were registered with an encrypted number code and de-identified prior 
to the study. All samples from patients included in the study were rendered anonymous. Thus, individuals could not be matched with their samples and their epidemiological and clinical data. The study was conducted according to the principles expressed in the Declaration of Helsinki, the Oviedo Convention on Human Rights, Biomedicine and the Slovene Code of Medical Deontology. Since only aggregated data were received and no additional samples or data were collected, the study was deemed to be low risk and the need for additional ethical permission from the National Medical Ethics Committee was waived.

Conflict of interest The authors declare that they have no competing interests.

Open Access This article is distributed under the terms of the Creative Commons Attribution 4.0 International License (http://creativeco mmons.org/licenses/by/4.0/), which permits unrestricted use, distribution, and reproduction in any medium, provided you give appropriate credit to the original author(s) and the source, provide a link to the Creative Commons license, and indicate if changes were made.

\section{References}

1. Li PKT, Chow KM, Van De Luijtgaarden MWM, et al. Changes in the worldwide epidemiology of peritoneal dialysis. Nat Rev Nephrol. 2017;13:90-103. https://doi.org/10.1038/nrnep h.2016.181.

2. See EJ, Johnson DW, Hawley CM, et al. Early peritonitis and its outcome in incident peritoneal dialysis patients. Perit Dial Int. 2017. https://doi.org/10.3747/pdi.2017.00029.

3. Li PK, Szeto CC, Piraino B, et al. ISPD peritonitis recommendations: 2016 update on prevention and treatment. Perit Dial Int. 2016;36:481-508. https://doi.org/10.3747/pdi.2016.00078.

4. Cho Y, Johnson DW. Peritoneal dialysis-related peritonitis: towards improving evidence, practices, and outcomes. Am J Kidney Dis. 2014;64:278-89. https://doi.org/10.1053/j. ajkd.2014.02.025.

5. Bargman JM, Hospital TG. Characteristics and outcomes of fungal peritonitis in a modern North American cohort. Perit Dial Int. 2015;35:78-84. https://doi.org/10.3747/pdi.2013.00179.

6. Tobudic S, Forstner C, Schranz H, Poeppl W, Vychytil A. Comparative in vitro fungicidal activity of echinocandins against $\mathrm{Can}$ dida albicans in peritoneal dialysis fluids. Mycoses. 2013;56:62330. https://doi.org/10.1111/myc.12079.

7. Chavada R, Kok J, Van Hal S, Chen SC. Seeking clarity within cloudy effluents: differentiating fungal from bacterial peritonitis in peritoneal dialysis patients. PLoS One. 2011;6:e28247. https ://doi.org/10.1371/journal.pone.0028247.

8. Giacobino J, Montelli AC, Barretti P, et al. Fungal peritonitis in patients undergoing peritoneal dialysis (PD) in Brazil: molecular identification, biofilm production and antifungal susceptibility of the agents. Med Mycol. 2016;54:725-32. https://doi.org/10.1093/ $\mathrm{mmy} / \mathrm{myw} 030$

9. Levallois J, Annie-Claire N-F, Labbé A-C, Laverdière M, Ouimet D, Vallée M. Ten-year experience with fungal peritonitis in peritoneal dialysis patients: antifungal susceptibility patterns in a North-American center. Int J Infect Dis. 2012;16:e41-3. https:// doi.org/10.1016/j.ijid.2011.09.016.

10. Basturk T, Koc Y, Unsal A, et al. Fungal peritonitis in peritoneal dialysis: a 10 year retrospective analysis in a single center. Eur Rev Med Pharmacol Sci. 2012;16:1696-700.

11. Kazancioglu R, Kirikci G, Albaz M, Dolgun R, Ekiz S. Fungal peritonitis among the peritoneal dialysis patients of four Turkish centres. J Ren Care. 2010;36:186-90. https://doi.org/10.111 1/j.1755-6686.2010.00193.x.

12. Xiao M, Fan X, Wang H, et al. Antifungal susceptibilities of Candida glabrata species complex, Candida krusei, Candida parapsilosis species complex and Candida tropicalis causing invasive candidiasis in China: 3 year national surveillance. J Antimicrob Chemother. 2015;70:802-10. https://doi.org/10.1093/jac/dku460.

13. Baer RA, Killen JP, Cho Y, Mantha M. Non-candidal fungal peritonitis in Far North Queensland: a case series. Perit Dial Int. 2013;33:559-64. https://doi.org/10.3747/pdi.2012.00024.

14. Matuszkiewicz-Rowinska J. Update on fungal peritonitis and its treatment. Perit Dial Int. 2009;29:161-5.

15. Miles R, Hawley CM, McDonald SP, et al. Predictors and outcomes of fungal peritonitis in peritoneal dialysis patients. Kidney Int. 2009;76:622-8. https://doi.org/10.1038/ki.2009.202.

16. Cho Y, Badve SV, Hawley CM, et al. Effects of climatic region on peritonitis risk, microbiology, treatment, and outcomes: a multicenter registry study. Perit Dial Int. 2013;33:75-85. https ://doi.org/10.3747/pdi.2011.00317.

17. Pappas PG, Kauffman CA, Andes DR, et al. Clinical practice guideline for the management of candidiasis: 2016 update by the Infectious Diseases Society of America. Clin Infect Dis. 2016;62:e1-50. https://doi.org/10.1093/cid/civ933.

18. Bassetti M, Marchetti M, Chakrabarti A, et al. A research agenda on the management of intra-abdominal candidiasis: results from a consensus of multinational experts. Intensive Care Med. 2013;39:2092-106. https://doi.org/10.1007/s0013 4-013-3109-3.

19. Solomkin JS, Mazuski JE, Bradley JS, et al. Diagnosis and management of complicated intra-abdominal infection in adults and children: guidelines by the Surgical Infection Society and the Infectious Diseases Society of America. Clin Infect Dis. 2010;50:133-64. https://doi.org/10.1086/649554.

20. Clinical and Laboratory Standards Institute (CLSI). Reference method for broth dilution antifungal susceptibility testing of yeasts. Approved standard-third edition. CLSI Doc M27-A3. 2008.

21. Davenport A, Wellsted D. Does antifungal prophylaxis with daily oral fluconazole reduce the risk of fungal peritonitis in peritoneal dialysis patients? The Pan Thames Renal Audit. Blood Purif. 2011;32:181-5. https://doi.org/10.1159/000328735.

22. Chang TI, Kim HW, Park JT, et al. Early catheter removal improves patient survival in peritoneal dialysis patients with fungal peritonitis: results of ninety-four episodes of fungal peritonitis at a single center. Perit Dial Int. 2011;31:60-6. https://doi. org/10.3747/pdi.2009.00057.

23. Garcia-Agudo R, Garcia-Martos P. Clinical and microbiological aspects of fungal peritonitis in peritoneal dialysis. Nefrología. 2009;29:506-17. https://doi.org/10.3265/Nefrologia 2009.29.6.5650.en.full.

24. Oygar DD, Altiparmak MR, Murtezaoglu A, Yalin AS, Ataman R, Serdengecti K. Fungal peritonitis in peritoneal dialysis: risk factors and prognosis. Ren Fail. 2009;31:25-8. https://doi. org/10.1080/08860220802546446.

25. Johnson DW, Cho Y, Mehrotra R. Is female sex really a risk factor for infectious death in peritoneal dialysis? Perit Dial Int. 2013;33:475-8. https://doi.org/10.3747/pdi.2013.00191.

26. Nessim SJ, Bargman JM, Austin PC, Nisenbaum R, Jassal SV. Predictors of peritonitis in patients on peritoneal dialysis: results of a large, prospective Canadian database. Clin J Am Soc Nephrol. 2009;4:1195-200. https://doi.org/10.2215/CJN.00910209.

27. Szeto C, Kong H. Peritoneal dialysis-related infection in the older population. Perit Dial Int. 2015;35:659-62.

28. Duquennoy S, Verger C, Ficheux M, Ryckelynck J, Lobbedez T. Is peritonitis risk increased in elderly patients on peritoneal dialysis? Report from the French language peritoneal dialysis registry 
(RDPLF). Perit Dial Int. 2016;36:291-6. https://doi.org/10.3747/ pdi.2014.00154.

29. Hsieh YP, Chang CC, Wen YK, Chiu PF, Yang Y. Predictors of peritonitis and the impact of peritonitis on clinical outcomes of continuous ambulatory peritoneal dialysis patients in Taiwan -10 years' experience in a single center. Perit Dial Int. 2014;34:85-94. https://doi.org/10.3747/pdi.2012.00075.

30. Zanger R. Hyponatremia and hypokalemia in patients on peritoneal dialysis. Semin Dial. 2010;23:575-80. https://doi. org/10.1111/j.1525-139X.2010.00789.x.

31. Chuang YW, Shu KH, Yu TM, Cheng CH, Chen CH. Hypokalaemia: an independent risk factor of enterobacteriaceae peritonitis in CAPD patients. Nephrol Dial Transplant. 2009;24:1603-8. https ://doi.org/10.1093/ndt/gfn709.

32. Ribeiro SC, Figueiredo AE, Barretti P, Pecoits-Filho R, De Moraes TP. Low serum potassium levels increase the infectious-caused mortality in peritoneal dialysis patients: a propensity-matched score study. PLoS One. 2015;10:e0127453. https ://doi.org/10.1371/journal.pone.0127453.

33. Pfaller MA, Castanheira M, Messer SA, Jones RN. In vitro antifungal susceptibilities of isolates of Candida spp. and Aspergillus spp. from China to nine systemically active antifungal agents: data from the SENTRY antifungal surveillance program, 2010 through 2012. Mycoses. 2015;58(4):209-214. https://doi.org/10.1111/ myc. 12299.

34. Pagès A, Iriart X, Molinier L, et al. Cost effectiveness of Candida polymerase chain reaction detection and empirical antifungal treatment among patients with suspected fungal peritonitis in the intensive care unit. Value Health. 2017;20:1319-28. https://doi. org/10.1016/j.jval.2017.06.009. 